\title{
HUBUNGAN PEMAHAMAN PELAYANAN DAN PANGGILAN DENGAN KESETIAAN PENGERJA DI GEREJA
}

\author{
Wirianto Ng, Gundari Ginting, Lukgimin Aziz \\ Sekolah Tinggi Teologi Sumatera Utara \\ mandiripenelitian@gmail.com
}

\begin{abstract}
This study aims to determine the existence relationship, both partially and mutually between understanding of servanthood and calling to serve and faithfulness in ministry of all workers. The place of this research was conducted at My Family GBI. The research method used was ex post facto pattern and quantitative. The concluded that there was a linear and significant relation between variable $X_{1}$ (understanding of servanthood) and variable $Y$ (faithfulness in ministry in church). So does $X_{1}$ and $X_{2}$ and $Y$. Every worker to realize that they were saved by God and repay God's kindness by serving Him in church. It is recommended that this research can be used as one of the guidance as a foundation of ministering life by servants in God's field.

Keywords: $\quad$ Calling to Serve, Faithfulness in Ministry, Understanding of Servanthood.
\end{abstract}

\begin{abstract}
Abstrak: $\quad$ Penelitian ini untuk mengetahui hubungan baik secara parsial maupun secara bersama-sama antara pemahaman pelayanan dan panggilan melayani dengan kesetiaan melayani. Tempat penelitian di GBI My Family. Metode penelitian yang digunakan adalah dengan pola ex post facto dan kuantitatif. Hasil penelitian menyimpulkan bahwa terdapat hubungan yang linier dan signifikan antara variabel $X_{1}$ dengan variabel $Y$ serta $X_{1}$ bersama $X_{2}$ dengan $Y$. Pengerja di gereja, sebaiknya menyadari bahwa mereka telah diselamatkan dan saatnya untuk membalas kebaikan Tuhan dengan melayani-Nya di gereja. Disarankan agar penelitian ini menjadi salah satu bahan pedoman sebagai landasan dalam kehidupan pelayanan oleh para pengerja di ladang Tuhan.
\end{abstract}

Kata kunci: Kesetiaan Melayani, Panggilan Melayani, Pemahaman Pelayanan

\section{PENDAHULUAN}

Setiap pengerja yang mengambil bagian dalam pelayanan tentunya juga menyadari akan adanya pengorbanan (sacrifice) yang harus diberikan dan merupakan konsekuensi dalam kehidupan pelayanan ini. Pengorbanan berupa waktu, tenaga dan materi (uang) sudah pasti harus diberikan oleh seorang pengerja di gereja di mana dia melayani. Namun, apapun bentuk dan seberapa besarnya pengorbanan yang diberikan oleh seorang pengerja (pelayan) tentunya 
tidak akan kembali dengan sia-sia (Band. Wahyu 3:11). Tuhan telah menyediakan upah dan mahkota bagi mereka yang sungguh-sungguh melayani-Nya. Kesetiaan melayani dan pemahaman melayani menjadi salah satu isu menarik dalam pembahasan di bidang gereja serta jabatan gerejani. ${ }^{1}$

Henry dan Tom Blackaby ${ }^{2}$ menyebutkan kata kesetiaan (faithfulness) dihubungkan dengan sebuah janji (a promise). “...Hendaklah engkau setia sampai mati, dan Aku akan mengaruniakan kepadamu mahkota kehidupan.” (Wahyu 2:10). Kesetiaan adalah tujuan jangka panjang. Kesetiaan adalah bertekun sampai akhir dengan ketaatan yang maksimal. ${ }^{3}$ Kesetiaan adalah tetap benar di hadapan Tuhan dan mentaati Firman-Nya saat seseorang merasa berkecil hati dan susah maupun pada saat senang dan sukses. Sedangkan kata "setia" (faithful) artinya tabah, berdedikasi, dapat diandalkan dan dapat dipercaya.

Kesetiaan melayani dan integritas menjadi identitas penting dalam diri pelayan seperti Yesus, ${ }^{4}$ demikian anjuran Gembala dalam berbagai kesempatan. Mungkin pengertian atau pemahaman dan tingkat kesetiaan melayani dari setiap pengerja (pelayan) di Gereja Bethel Indonesia (GBI) My Family berbeda-beda.

Pada kenyataannya juga, pengerja-pengerja ada yang memilih berhenti melayani ataupun keluar dari pelayanan di GBI My Family (sejak gereja tersebut ditahbiskan di bulan September 2016), menunjukkan persentase-persentase yang bervariasi, terutama di tahun 2019 yang menunjukkan persentase yang signifikan (bila dibandingkan dengan tahun-tahun sebelumnya). Data jumlah pengerja yang

\footnotetext{
1 Dessy Handayani, "Isu-isu Kontemporer dalam Jabatan Gerejawi," Kurios 3 No.1 (2015): 66, https://doi.org/10.30995/kur.v3i1.28.

2 Henry Blackaby dan Tom Blackaby, The Man God Uses (Singapore: B\&H Books, 2001), 59.

3 I Putu Ayub Darmawan, "Jadikanlah Murid: Tugas Pemuridan Gereja Menurut Matius 28:18-20," Evangelikal: Jurnal Teologi Injili dan Pembinaan Warga Jemaat 3, no. 2 (2019): 150, https://doi.org/10.46445/ejti.v3i2.138.

4 Manase Gulo, "Prinsip Integritas Berdasarkan Injil Matius 5:17-48 Dan Implementasinya Bagi Pelayan Tuhan Masakini.," Manna Rafflesia 4, no. 1 (2017): 23, https://doi.org/10.38091/man_raf.v4i1.79.
} 
diperoleh dari Sekretariat GBI My Family selama tiga tahun terakhir (2017-2019) dari ketiga cabang yang ada (yakni cabang Grand Palladium, Negara dan Tiara Convention Centre) telah dirangkum dan dapat dilihat dari tabel berikut:

Tabel 1.

Data Jumlah Pengerja GBI My Family

\begin{tabular}{|c|c|c|c|}
\hline Tahun & Jumlah Pengerja & $\begin{array}{c}\text { Pengerja yang } \\
\text { berhenti/keluar }\end{array}$ & $\begin{array}{c}\text { Persentase } \\
(\mathbf{\%})\end{array}$ \\
\hline 2017 & 167 & 5 & 2.99 \\
\hline 2018 & 232 & 12 & 5.17 \\
\hline 2019 & 220 & 68 & 30.91 \\
\hline
\end{tabular}

Observasi awal terhadap tujuh pelayan dari sejumlah yang keluar seperti tabel 1 di atas, ditemukan dokumen resignation letter dan varian jawaban. Jawaban tersebut direduksi seperti dalam tabel.

Tabel 2.

Alasan Pengerja GBI My Family Berhenti

\begin{tabular}{|c|c|c|}
\hline Tahun & Jumlah Pengerja & Alasan Pengerja yang berhenti/keluar \\
\hline 2017 & $\begin{array}{c}\text { Wawancara } 1 \text { orang } \\
\text { dari } 5 \text { yang } \\
\text { berhenti/keluar }\end{array}$ & $\begin{array}{l}\text { 1. Tidak memiliki kesan yang mendalam } \\
\text { terhadap program } \\
\text { 2. Ada tawaran dari Lembaga lain }\end{array}$ \\
\hline 2018 & $\begin{array}{l}\text { Wawancara } 2 \text { orang } \\
\text { dari } 12 \text { yang } \\
\text { berhenti/keluar }\end{array}$ & $\begin{array}{l}\text { 1. Ada tawaran dari Lembaga lain } \\
\text { 2. Jenuh } \\
\text { 3. Tidak cocok dengan pemahaman pribadi } \\
\text { tentang melayani } \\
\text { 4. Tidak sesuai dengan visi } \\
\text { 5. Tidak memahami visi Gereja }\end{array}$ \\
\hline 2019 & $\begin{array}{l}\text { Wawancara } 4 \text { orang } \\
\text { dari } 68 \text { yang } \\
\text { berhenti/keluar }\end{array}$ & $\begin{array}{l}\text { 1. Jenuh dan mulai bosan } \\
\text { 2. Tidak sesuai dengan visi } \\
\text { 3. Tidak ada panggilan. Belum yakin akan } \\
\text { panggilan melayani } \\
\text { 4. Jadwal dan program yang ada tidak sesuai }\end{array}$ \\
\hline
\end{tabular}




\begin{tabular}{|l||l||}
\hline \hline & dengan keinginan dan tujuan pribadi \\
\hline
\end{tabular}

Melihat fakta awal dalam oberservasi tersebut, maka peneliti merencanakan satu penelitian terhadap masalah yang terjadi yakni pergantian pengerja yang relatif besar terjadi. Dari fakta ini Tim Peneliti menduga adanya pemahaman pelayanan, panggilan melayani dengan kesetiaan melayani yang kurang pada diri pengerja. Tiga faktor ini kemudian menjadi dasar berangkat penelitian lapangan dan menjadikannya sebagai variabel penelitian. Peneliti menduga bahwa jika pemahaman pelayanan, panggilan melayani dengan kesetiaan melayani pada tingkat yang baik, maka tingkat keluar atau masuknya pengerja semakin kecil terjadi.

\section{METODE}

Metode penelitian yang dilakukan adalah menggunakan metode penelitian kuantitatif dengan pendekatan ex post facto, secara singkat artinya "from a thing done afterward." ${ }^{5}$ Hal ini dilakukan karena data yang diambil dan dikaji merupakan data yang sudah berlalu atau sudah dialami namun masih berlangsung sampai penelitian ini dilakukan. ${ }^{6}$ Metode penelitian kuantitatif ditempuh untuk menemukan jawaban dari masalah penelitian dengan data berupa angka dengan bantuan statistik, ${ }^{7}$ dimana pengukuran menggunakan skala Likert.

5 Kenneth Jost, "Ex Post Facto," dalam The Supreme Court A to Z, 5 ed. (CQ Press, 2014), 197, https://doi.org/10.4135/9781452234373.n131.

${ }^{6}$ Anthony A. Braga, David M. Hureau, dan Andrew V. Papachristos, "An Ex Post Facto Evaluation Framework for Place-Based Police Interventions," Evaluation Review 35, no. 6 (2012): 593, https://doi.org/10.1177/0193841X11433827. 287.

7 Wahidmurni, "Penerapan Metode Penelitian Kuantitatif," Repository UIN Malang 1, no. 1 (2017): 
Tempat penelitian ini di GBI My Family Medan. Pemilihan ini dilakukan karena menyangkut efisiensi dan efektifitas waktu dan tempat. Pelaksanaan penelitian dilakukan pada Desember 2019-Juni 2020. Populasi penelitian ini adalah pengerja GBI My Family dari tiga cabang yang ada yakni cabang Grand Palladium, Negara dan Tiara Convention Centre berjumlah 152 orang.

Tabel 3

Populasi Penelitian Pengerja GBI My Family

\begin{tabular}{|c|c|c|c|c|}
\hline No. & Cabang & Laki-Laki & Perempuan & $\begin{array}{l}\text { Jumlah } \\
\text { (orang) }\end{array}$ \\
\hline 1. & Grand Palladium & 38 & 45 & 83 \\
\hline 2. & Negara & 15 & 29 & 44 \\
\hline 3. & Tiara Convention Centre & 7 & 18 & 25 \\
\hline \multicolumn{4}{|c|}{ Jumlah } & 152 \\
\hline
\end{tabular}

Menurut Arikunto "sampel adalah sebagian atau wakil populasi yang diteliti." ${ }^{\prime 8}$ Kemudian Sugiono menyebutkan "dalam penelitian kuantitatif, sampel adalah bagian dari jumlah dan karakteristik yang dimiliki oleh populasi tersebut."9 Untuk itu, maka akan diambil sampel sebanyak 25\% dari keseluruhan jumlah pengerja dari tiga cabang GBI My Family dan yang diambil secara acak yaitu $25 \% \times 152$ orang $=38$ orang. Sehingga letak dan pengambilan sampel dalam penelitian ini adalah 25\% dari setiap cabang GBI My Family tahun 2019. Data dikumpulkan dengan tehnik pembagian angket. Sedangkan pengujian data dalam

${ }^{8}$ Arikunto Suharsimi, "Prosedur Penelitian : Suatu Pendekatan Praktik (Edisi Revisi)," Rineka Cipta, 2010, 174, https://doi.org/10.1017/CBO9781107415324.004.

9 Sugiono P.D, Metode penelitian pendidikan pendekatan kuantitatif.pdf, Metode Penelitian Pendidikan Pendekatan Kuantitatif, Kualitatif Dan R\&D, 2014, 209. 
penelitian ini adalah metode statistik inferensial yakni statistik parametris. ${ }^{10}$ Dimana statistik parametris digunakan untuk menguji parameter populasi melalui statistik (yakni data yang diperoleh dari sampel), atau menguji ukuran populasi melalui data sampel. Dilakukan dengan Uji Normalitas, uji Linieritas Dan Keberartian Regresi sebelum pada tahap uji hipotesa.

\section{HASIL}

Dalam penelitian lapangan ditemukan fakta menarik melalui penyebaran angket. Dari perhitungan koefisien korelasi antara variabel $\mathrm{X}_{1}$ (Pemahaman Pelayanan) dengan variabel Y (Kesetiaan Melayani Di Gereja), dapat diketahui bahwa nilai dari koefisien korelasi tersebut atau rhitung adalah sebesar 0,677. Dengan nilai dari rhitung $(0,677) \geq \mathrm{r}_{\text {tabel }}(0,361)$, maka dapat ditetapkan bahwa korelasi $\mathrm{X}_{1}$ dengan $\mathrm{Y}$ adalah Signifikan dan mempunyai hubungan yang berarti sebesar 6,2. Perhitungan koefisien korelasi antara variabel $\mathrm{X}_{2}$ (Panggilan Melayani) dengan variabel Y (Kesetiaan Melayani Di Gereja) sebesar 0,863. Nilai dari $\mathrm{r}_{\text {hitung }}(0,863) \geq \mathrm{r}_{\text {tabel }}(0,361)$, maka dapat ditetapkan bahwa korelasi $\mathrm{X}_{2}$ dengan Y adalah Signifikan dan mempunyai hubungan Berarti, sebesar 9,12. Perhitungan korelasi ganda antara variabel $\mathrm{X}_{1}$ (Pemahaman Pelayanan) dan variabel $\mathrm{X}_{2}$ (Panggilan Melayani) berhubungan secara bersama-sama dengan variabel Y (Kesetiaan Melayani Di Gereja), diperoleh nilai dari $\mathrm{R}_{\mathrm{y} 1.2}^{2}$ adalah 0,32 . Dari nilai $\mathrm{R}_{\mathrm{y} 1.2}^{2}$ tersebut, maka koefisien determinasinya adalah $10,24 \%$. Dari perolehan hasil ini, maka dapat disimpulkan bahwa koefisien korelasi ganda adalah berarti dan terdapat hubungan yang Berarti antara variabel $\mathrm{X}_{1}$ (Pemahaman

10 Sugiyono, "Metode Penelitian Kuantitatif,Kualitatif dan R\&D," Ke-26, 2018, 208. 
Pelayanan) dan variabel $\mathrm{X}_{2}$ (Panggilan Melayani) secara bersama-sama dengan variabel Y (Kesetiaan Melayani Di Gereja).

Dari hasil perhitungan tersebut, uji kecenderungan terhadap variabel kesetiaan melayani didapat seperti dalam tabel.

Table 4

Uji Kecenderungan Variabel Y (Kesetiaan Melayani)

\begin{tabular}{|c|c|c|c|c|}
\hline \hline Kelas & Interval Kelas & $\mathbf{f}_{\mathbf{o}}$ & $\mathbf{f \%}$ & Kategori \\
\hline \hline 1 & $>113$ & 17 & $57 \%$ & Baik \\
\hline \hline 2 & $105-112$ & 4 & $13 \%$ & Cukup Baik \\
\hline \hline 3 & $97-104$ & 4 & $13 \%$ & Kurang Baik \\
\hline 4 & $<96$ & 5 & $17 \%$ & Tidak Baik \\
\hline \hline & Jumlah & $\mathbf{3 0}$ & $\mathbf{1 0 0 \%}$ & \\
\hline
\end{tabular}

Dari data di atas maka penelitian ini menyatakan bahwa pemahaman akan arti dari pelayanan mempunyai hubungan dengan kesetiaan terhadap pelayanan itu. Termasuk panggilan untuk melayani juga ada hubungannya dengan kesetiaan di bidang pelayanan Gereja. Untuk kedua variabel (pemahaman pelayanan dan panggilan melayani) dari hasil penelitian didapati mempunyai hubungan yang erat dan signifikan dengan kesetiaan melayani.

\section{PEMBAHASAN}

Berikut ini akan dibahas berdasarkan data di atas, menurut variable penelitian secara berurut yakni hubungan Pemahaman Pelayanan dan Panggilan Melayani dengan Kesetiaan Melayani.

\section{Kesetiaan Melayani}

Jika setiap orang menginginkan semuanya bertumbuh secara berkesinambungan, maka diperlukan usaha yang konsisten, kesetiaan dan 
komitmen. Sama halnya jika melihat dan mencontohkan pembuat batu mulia, mereka memerlukan waktu dan konsistensi dalam proses produksi dari bahan baku hingga menjadi perhiasan. Demikian halnya bagi semua pelayan atau pengerja di gereja, mereka haruslah konsisten dalam melayani, setia dan menunjukkan komitmen dalam kehidupan pelayanan mereka. Dalam hal kesetiaan tidak lupa memerlukan ketegasan hati sehingga teguh dalam mencapai tujuannya bagi pelayanan. ${ }^{11}$ Kesetiaan sangatlah bernilai dan memerlukan kerja keras. Itulah kenapa Yesus menempatkan kesetiaan bersamaan dengan keadilan dan belas kasihan (Mat.23:23). Kesetiaan adalah buah Roh (Gal.5:22) dan dipuji dalam kehidupan tokoh-tokoh hebat di dalam Alkitab seperti Abraham, Yusuf, Musa dan Daniel.

Pengerja atau pelayan di gereja harus bisa menunjukkan sifat kesetiaan mereka dalam pelayanan dengan melaksanakan seluruh tanggung jawab, dan setia di dalam janji maupun perkataan dan perbuatan. Ini berkolerasi dengan sifat dari tokoh-tokoh hebat di dalam Alkitab seperti yang telah disebutkan oleh Emmanuel Oladipo. ${ }^{12}$ Adapun nas Alkitab yang memberikan contoh mengenai kesetiaan manusia, bisa dilihat di dalam Matius 25:20-21. Oleh sebab itu, para pengerja atau pelayan di gereja harus bisa menunjukkan kesetiaan melayani dengan melaksanakan semua tanggung jawab yang diberikan kepada mereka.

Pengertian kesetiaan dari sudut pandang Cho dan Goodall dijelaskan sebagai fondasi iman. ${ }^{13}$ Di samping merupakan pondasi iman, "Faithfulness is a

11 Kejar Hidup Laia, "Sikap Hamba Tuhan terhadap Jemaat yang Mundur dari Pelayanan," Illuminate 3, no. 1 (2020): 53, https://doi.org/621-7732. 2014).

12 Baca Emmanuel Oladipo, Flawed Saints, ed. oleh Hans Wuysang (Jakarta: Pancar Pijar Alkitab,

${ }^{13 K e s e t i a a n ~(f a i t h f u l n e s s) ~ m e r u p a k a n ~ p o n d a s i ~ i m a n . ~ B u a h ~ k e s e t i a a n ~(s e t i a ~ d a l a m ~ t i n d a k a n) ~ a d a l a h ~}$ dapat dipercaya dan karakter yang tetap dalam kehidupan orang percaya. Kata Yunani dari buah kesetiaan 
sign of maturity" yang mana kesetiaan juga merupakan tanda kedewasaan. Kesetiaan merupakan tanda kedewasaan dan pengerja di gereja yang setia tentunya akan menerapkan prinsip kedewasaan ini. ${ }^{14}$

Selain setia, kriteria lain yang diperlukan adalah: "Dependability, punctuality, and being responsible are all part of the package of faithfulness." Misalnya sifat/prilaku yang dapat diandalkan, tepat waktu, dan bertanggung jawab semuanya merupakan bagian dari paket kesetiaan. Setiap pelayan atau pengerja di gereja juga diharapkan memiliki kriteria-kriteria tersebut yang bisa tercermin dalam kehidupan pelayanan (Band.Luk.16:10). Upah dari kesetiaan adalah mengetahui bahwa setiap orang percaya yang telah setia dan mengerti suatu hari nanti, Tuhan akan berkata, "Selamat datang, hamba-Ku yang setia!"

Tidak dapat dipungkiri bahwa Tuhan Yesus merupakan contoh terbaik ${ }^{15}$ dari kesetiaan sebab Tuhan tidak pernah mengingkari janji-Nya kepada setiap orang percaya. Paulus mengingatkan temannya Timotius bahwa bahkan "jika kita tidak setia, Dia tetap setia, karena Dia tidak dapat menyangkal diri-Nya" (2 Tim.2:13).

Ide menjadi teman/sahabat Tuhan sering membingungkan banyak orangorang percaya dan beriman pada Kristus. Setiap pengerja dan pelayan juga harus taat dan percaya kepada-Nya dalam segala hal yang mereka lakukan termasuk dalam hal pelayanan di gereja. Tuhan menginginkan semua pengerja di gereja

adalah pistis, yang diterjemahkan sebagai "iman, keyakinan dan dipercaya" (faith, belief and trusted). Mereka yang setia selalu dapat diandalkan (dependable) dan kita bisa mempercayai mereka.( Yonggi Cho dan Wayde Goodall, Faith: Believing In The God Who Works On Your Behalf (Wisconsin: BroadStreet Publishing Group, LLC, 2017), 143.

${ }^{14}$ Band. Laia, "Sikap Hamba Tuhan terhadap Jemaat yang Mundur dari Pelayanan," 45-48 Ketika menjelaskan Eks Yoh.6.

15 Kalis Stevanus, "Mengimplementasikan Pelayanan Yesus Dalam Konteks Misi Masa Kini Menurut Injil Sinoptik," FIDEl: Jurnal Teologi Sistematika dan Praktika 1, no. 2 (2018): 290, https://doi.org/10.34081/fidei.v1i2.21. 
berlaku sebagai sahabat-sahabat-Nya. Sebab seorang sahabat meraruh kasih setiap waktu. Yang terpenting, tiap pelayan harus setia dan taat kepada Tuhan sampai mati seperti Kristus taat sampai di kayu salib. ${ }^{16}$ Suatu hari kelak pelayan tidak akan dinilai dari kesuksesan, pencapaian akademis atau bahkan semua yang sudah pernah diberikan.

Pemahaman kesetiaan dan menjelaskan bahwa setiap orang percaya harus setia dalam segala hal, baik besar maupun kecil (faithful in all things, big and small). Dengan pemahaman ini, dalam konteks pelayan di kaum muda, Prihanto menyatakan akan memudahkan pelayan untuk bertahan dalam satu wadah pelayanan meski didera banyak tantangan dan masalah. ${ }^{17}$ Demikian juga semua pengerja atau pelayan seharusnya bisa menunjukkan bahwa mereka dapat dipercaya bahkan dalam pekerjaan pelayanan yang sekecil apapun. Tuhan menilai karakter seseorang melalui bagaimana mereka melakukan segala sesuatu. Nats ini menjelaskan pentingnya penatalayanan (stewardship) yang dapat dipercaya (trustworthy) akan memberikan upah bagi setiap pengerja atau pelayan, baik dalam kehidupan sekarang ini dan upah di sorga nantinya.

Yesus memberikan perumpamaan mengenai talenta (Mat.25:14-30) yang mana melalui cerita ini memberikan orang percaya beberapa pelajaran penting yakni: Tuhan memberikan setiap orang percaya kemampuan dan kesempatan yang berbeda, dan Dia mengharapkan agar mereka menggunakannya untuk melayani Dia. Tuhan akan memberikan mereka upah menurut seberapa mereka bertumbuh secara spiritual (rohani) dan melayani-Nya dalam kehidupan mereka. Seorang

\footnotetext{
16 Made Nopen Supriadi dan Iman Kristina Halawa, "Makna Penderitaan Kristus Dalam 1 Petrus 2:18-21," Manna Rafflesia 5, no. 1 (2018): 86, https://doi.org/10.38091/man_raf.v5i1.99.

${ }_{17}$ Agus Prihanto, "Peran Proses Mentoring Pemimpin Kaum Muda Bagi Perkembangan Pelayanan Pemuda Di Gereja," Jaffray 16, no. 2 (2018): 200, http://dx.doi.org/10.25278/j]71.v16i2.258.
} 
hamba yang "malas" yang sudah menggunakan waktu dan kesempatan yang diberikan kepadanya dengan sia-sia dan tidak menuruti perintah Tuhan disebut "hamba yang jahat dan malas" dan akan dihukum.

Dari uraian di atas mengenai kesetiaan dan melayani, maka dapat dilihat adanya hubungan antara kata kesetiaan dan melayani yang mana jika digabungkan

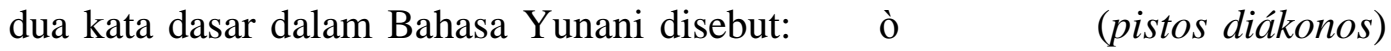
yang berarti "pelayan yang setia". Jadi para pengerja di gereja diharapkan menjadi pelayan yang setia. Ini berarti bahwa kesetiaan dari diri seorang pengerja akan tercermin dalam pelayanannya.

Untuk memperjelas hal tersebut disini diberikan enam poin penekanan yakni: pertama Allah mengasihi orang yang setia karena Dia adalah setia. Kedua, hanya ada satu jalan untuk belajar setia kepada Allah, yaitu dengan belajar setia kepada sesama. Ketiga, Pelayan harus belajar setia dan loyal kepada siapapun yang berwenang di atasnya. Keempat, kesetiaan menuntut pengorbanan. Kelima, Allah memberkati orang yang setia. Dan kelima, suatu waktu kesetiaan itu akan diuji.

\section{Pemahaman Pelayanan}

Horsfall memberikan definisi pelayanan menurut pendapatnya yakni: "Servanthood is the state of being a servant; the attitude of mind, disposition of heart and daily practice of someone who serves."18 Bisa diartikan bahwa pelayanan merupakan keadaan seorang pelayan; yang memiliki sikap pikiran, karakter dari hati dan merupakan kebiasaan sehari-hari dari seseorang yang melayani. Pelayanan merupakan sesuatu yang mana semua orang percaya

18 Tony Horsfall, Servant Ministry: A Portrait Of Christ And A Pattern For His Followers (Abingdon: Bible Reading Fellowship, 2013), 18. 
dipanggil, bukan hanya mereka yang melayani secara penuh waktu (full time). Ini berarti bahwa mengerti tentang pelayanan berarti hal yang vital untuk kesehatan dan kebaikan dari gereja lokal. Setiap anggota harus menghargai peranan mereka sebagai pelayan Tuhan. Dengan pemahaman pelayanan yang baik maka penghargaan dan kesetiaan terhadap pelayanan itu akan tumbuh. Ini ibarat pepatah menyatakan, 'tak kenal maka tak saying.'

Elmer L. Town dan Dave Earley menyebutkan "The reward for work well done is the opportunity to do more"19 (hadiah dari pekerjaan yang diselesaikan dengan baik merupakan kesempatan untuk melakukannya lebih banyak lagi) dan Amsal 10:4. Menurut Towns dan Earley, mungkin orang Kristen akan merasa terkejut mengetahui bahwa Tuhan tidak peduli di mana mereka bekerja (where we work) karena Dia lebih peduli bagaimana mereka bekerja (how we work). Lokasi tidaklah sepenting di mana mereka ditempatkan. Karir tidak sepenting sifat atau karakter mereka. Yang terpenting adalah bagaimana mereka belajar berdoa agar menjadi pengerja dan pelayan Kristen yang benar (Band. Ams.13:4; 12:27 dan $15: 19$.

Semua pengerja atau pelayan di gereja hendaknya memiliki sifat atau karakter yang mencerminkan hal yang positif untuk kemuliaan Tuhan di dalam kehidupan pelayanan mereka. Berkenaan dengan ini, Tony Cooke mengetengahkan empat belas sifat atau karakter yang seharusnya dimiliki oleh semua pengerja atau pelayan di gereja (di mana karakter-karakter ini akan menjadikan mereka sebagai aset yang tidak ternilai di manapun mereka ditempatkan dalam pelayanan atau disebut sebagai karakter positif (positive

19 Elmer L Towns dan Dave Earley, Praying for Your Job-Prosperity, Fulfillment, Happiness (Shippensburg: Destiny Image Publishers, Inc, 2011), 93. 
characters traits). Cooke menjabarkan yakni: 1.) Loyal, 2.) Have excellent attitude, 3.) Faithful, 4.) Play well with others, 5.) Have a servant's heart, 6.) Energetic and enthusiastic, 7.) Balanced, 8.) Flexible and growth-oriented, 9.) Internally motivated, 10.) Good communicators, 11.) Multiply themselves, 12.) People of integrity and honesty, 13.) Exercise wisdom in their pulpit ministry dan 14.) Exercise discretion. ${ }^{20}$ Untuk memperjelas poin-poin tersebut di atas, berikut akan diberikan penjelasannya:

1. Loyal (penuh kesetiaan dan tulus hati, Band 2 Taw.19:9).

Alkitab mencatat banyak laki-laki dan perempuan yang mendemonstrasikan sifat setia dan tulus yang harus dimiliki oleh seorang pelayan di dalam pelayanannya, sebagai contoh Rut menunjukkan kesetiaanya kepada mertuanya; Naomi (Rut 1:16-17). Itai yang setia dengan tulus hati kepada rajanya (2 Sam.15:19-21) dan Yoab (2 Sam.12:26-28) di mana dia tidak ingin mendapatkan penghargaan dari apa yang telah dicapainya. Yoab hanya ingin memberikan kehormatan kepada pemimpinnya. Semua pelayan atau pengerja di gereja dewasa ini juga harus bisa belajar dan mengaplikasikan prinsip kesetiaan yang sama dari contoh di atas dalam pelayanannya, yakni setia kepada gembala maupun pemimpinnya.

2. Have excellent attitude (memiliki sikap yang baik sekali).

Pentingnya sikap tidak dapat disepelekan; sikap merupakan salah satu faktor terpenting untuk menentukan kualitas kontribusi seorang pelayan di dalam sebuah gereja. Contohnya, akan dihadapkan pada situasi di mana seorang pelayan A memiliki talenta yang luar biasa tetapi memiliki sikap (attitude) yang jelek, atau pelayan B yang memiliki talenta yang biasa-biasa saja tetapi memiliki sikap yang

20 Tony Cooke, Qualified: Serving God With Integrity And Finishing your Course With Honor (Tulsa: Harrison House, Inc, 2012), 99-183. 
luar biasa. Tentunya yang akan dipilih oleh gembalanya adalah pelayan B karena mereka tahu sehebat apapun talenta yang dimiliki oleh seorang pelayan, maka dia pasti akan menciptakan masalah dalam kelompoknya jika dia memiliki sikap yang jelek.

Memiliki sikap (attitude) yang baik dalam pelayanan, semua pengerja atau pelayan haruslah bisa belajar dari tokoh Daud yang menggembalakan dengan ketulusan hati dan kecakapan tangannya seperti yang tertulis dalam Mazmur 78:72. Daud melakukannya dengan sikap yang tulus (pureness) dan tidak memiliki agenda tersembunyi lainnya.

\section{Faithful (setia).}

Kedua nas di dalam Alkitab yang menyebutkan karakter setia yakni Matius 25:21 dan Lukas 16:10-12. Semua pengerja atau pelayan di gereja diharapkan memiliki karakter atau sifat yang setia. Adapun ciri-ciri orang yang setia seperti dalam tabel.

Tabel 5 Ciri Pelayan Yang Setia

\begin{tabular}{|l|l|}
\hline \multicolumn{1}{|c|}{ Karakter } & \multicolumn{1}{|c|}{ Attitude } \\
\hline $\begin{array}{l}\text { Menepati janji; bisa diandalkan; dapat } \\
\text { dipercaya }\end{array}$ & $\begin{array}{l}\text { Dapat diandalkan untuk menyelesaikan } \\
\text { tugas dan bisa bergantung kepada mereka } \\
\text { untuk menyelesaikan tugas yang diberikan }\end{array}$ \\
\hline $\begin{array}{l}\text { Mendedikasikan sepenuh hati dalam } \\
\text { melakukan tugas dan tanggung jawab. }\end{array}$ & $\begin{array}{l}\text { Tuntas, bukan hanya memulai dengan } \\
\text { hebat tapi mengakhiri dengan hebat dan } \\
\text { tidak meninggalkan tanggung jawab di } \\
\text { tengah jalan }\end{array}$ \\
\hline Tekun dalam bekerja & Menyelesaikan tugas \\
\hline $\begin{array}{l}\text { Jujur dan dapat dipercaya, tidak penuh } \\
\text { tipu muslihat. }\end{array}$ & Bertanggung jawab terhadap tugas \\
\hline $\begin{array}{l}\text { Tepat waktu; selalu hadir tepat waktu } \\
\text { dan sanggup menyelesaikan sesuai } \\
\text { dengan batas (tenggat) waktu }\end{array}$ & Mengerjakan melebihi harapan \\
\hline
\end{tabular}

Tingkat kesetiaan akan menentukan nilai dari pelayanan seorang pelayan atau pengerja di gereja. Jika kesetiaan seseorang menurun, maka nilainya akan 
menurun juga. Tetap berlaku setia, dapat diandalkan dan menuntaskan semua pekerjaan maka Tuhan akan memakai mereka secara luar biasa.

4. Play well with others (Bergaul baik dengan sesama).

Ada tiga kategori atau kelompok orang di mana sebagai seorang pelayan atau pengerja harus bisa bergaul baik yakni: pertama: harus bisa bergaul dan bekerja dengan baik bersama gembala (band. Ibr.13:17). Kedua: harus bisa bergaul baik dengan pemimpin (leader) lainnya dan juga rekan sepengerja/sepelayanan (Band.Rom.12:18. Ketiga: harus memiliki hubungan yang baik dengan seluruh jemaat gereja (Band.1 Kor.13:1-7).

5. Have a servant's heart (memiliki hati seorang hamba).

Memiliki hati seorang hamba akan bersedia melayani di belakang layar dan bersedia mengerjakan pekerjaan apapun dan merupakan pekerja yang rajin. Karena mereka melakukan semua pekerjaan hanya untuk Tuhan, maka mereka tidak peduli apakah dilihat orang atau tidak.

6. Energetic and enthusiastic (penuh energi dan antusias).

Pelayan yang penuh energi dan antusias akan mampu melakukan seluruh pekerjaan mereka dengan tuntas dan baik. Memiliki etos kerja yang kuat, menghasilkan hasil-hasil yang luar biasa. Ini sesuai dengan apa yang tertulis dalam Amsal 22:29.

\section{Balanced (seimbang).}

Pelayan atau pengerja yang kurang seimbang dalam kehidupannya merupakan calon kuat untuk menjadi lelah. Tuhan ingin mereka bekerja keras, tetapi Dia tidak menginginkan mereka menjadi ketagihan kerja (workaholics). Kehidupan dan pelayanan bukanlah semata-mata mengenai "hasil (output)". Mereka juga 
memerlukan kualitas "masukan (input)". Saat mereka mencari keseimbangan dalam prioritas mengenai pekerjaan dan keluarga, mereka akan berhasil melayani pasangan mereka, anak-anak mereka dan orang lain. Harus diingat, keseimbangan merupakan kunci vital untuk memberikan kesehatan fisik dan emosional dan menikmati masa yang panjang dalam pelayanan.

8. Flexible and growth-oriented (fleksibel dan berorientasi pada pertumbuhan). Semua pengerja atau pelayan di gereja diminta untuk belajar seumur hidup, artinya selalu mencari dan belajar hal baru, haus akan informasi yang dapat memberikan mereka keunggulan dalam area pelayanan. Mereka juga harus bisa menerima koreksi dari gembala dan menerimanya dengan senang hati, bersedia menerima ide dan cara baru dalam melakukan suatu pekerjaan, bisa beradaptasi dengan orang lain, bersedia melakukan tugas baru atau peran baru untuk kebaikan gereja, selalu aktif dalam mencari perbaikan-perbaikan (menjadi lebih efektif dan produktif) serta mengalami peningkatan kerohanian yakni memiliki hubungan yang terkini (up to date) dan semangat (vibrant) dengan Tuhan melalui pendalaman Alkitab dan doa untuk menghasilkan buah roh dalam kehidupan mereka.

9. Internally motivated (termotivasi secara internal).

Bagian dari termotivasi secara internal berarti harus bisa memulai dari diri sendiri (self-starter). Dengan kata lain, setiap pengerja atau pelayan harus tahu bagaimana menginspirasi diri mereka sendiri untuk melakukan pekerjaan dengan baik dan tidak harus menunggu orang lain untuk memotivasi mereka. Seorang pelayan atau pengerja tidak perlu menunggu hingga dia diminta untuk melakukan 
sesuatu; mereka melihat apa yang harus dikerjakan dan mengambil inisiatif untuk melakukannya.

10. Good communicators (mampu berkomunikasi dengan baik).

Nas Alkitab yang memberikan pengertian tentang berkomunikasi dengan baik yakni di dalam Maleakhi 3:16. Orang yang suka berbicara bukan berarti orang yang mampu berkomunikasi dengan baik. Kenyataanya, seorang komunikator yang baik tidak memulai dengan berbicara atau mengekspresikan dirinya, melainkan dimulai dengan mendengar secara atentif, mengamati dan mendengar saat orang lain berbicara. Pengerja atau palayan di gereja diminta untuk menjadi komunikator yang baik. Untuk menjadi seorang komunikator yang baik, hendaknya belajar untuk selalu berbicara secara akurat, spesifik dan tepat saat berkomunikasi. Dan sangatlah penting bagi kelompok pemimpin untuk berkomunikasi dengan baik saat harus menjalankan sebuah gereja.

\section{Multiply themselves (bermultiplikasi).}

Dengan melatih yang lain untuk melakukan tugas atau mendelegasikan tanggung jawabnya kepada orang lain. Ide untuk memultiplikasi pemimpin bukanlah hal baru. Ini yang dilakukan oleh Musa (Kel.18) dan juga apa yang Yesus lakukan dengan murid-murid-Nya. Yesus memanggil kedua belas murid-Nya untuk mendengar dan mengobservasi. Dia mengajari mereka dan akhirnya menyediakan kesempatan secara periodik untuk mempraktekkan apa yang mereka lihat dan pelajari. Hingga akhirnya, Yesus menyerahkan semua tugas dan tanggung jawab sepenuhnya kepada mereka. Setelah semua murid-Nya diperlengkapi, Yesus berkata kepada murid-murid-Nya: “...Sama seperti Bapa mengutus Aku, demikian juga sekarang Aku mengutus kamu.” (Yoh.20:21). 
12. People of integrity and honesty (mereka yang penuh integritas dan kejujuran).

Semua pengerja dan pelayanan di gereja diminta untuk memiliki kriteria atau sikap yang penuh integritas dan kejujuran seperti yang disebutkan di dalam Mazmur 51:6 dan Amsal 12:22. Hal yang sama juga disebutkan oleh Feucht dan Byrd $^{21}$ yang menyatakan "integrity starts at a heart, a mind, and a primarily motivational level. It is the unwavering determination to do what is right" yang bisa diartikan dengan integritas dimulai dari hati, pikiran, dan terutama tingkat motivasi. Integritas adalah tekad tak tergoyahkan untuk melakukan apa yang benar. Jika setiap pengerja atau pelayan di gereja selalu jujur dan memiliki integritas penuh, mereka akan memiliki testimoni yang sama yang dimiliki oleh Samuel (1 Sam.12:2-5). Di akhir pelayanan mereka, mereka bisa bertanya, "Siapakah yang telah kuperas? Siapakah yang telah kuperlakukan dengan kekerasan?" dan jawabannya ialah, “Tidak, kamu telah jujur di sepanjang hidupmu dan telah hidup di atas celaan.”

13. Exercise wisdom in their pulpit ministry (mempraktekkan hikmat dalam pelayan mimbar). ${ }^{22}$

Tidak semua pengerja atau pelayan yang terlibat dalam pelayanan akan menjadi pengkhotbah atau guru sekolah minggu. Di dalam 1 Petrus 4:11, Petrus menyebutkan mereka yang melayani Tubuh Kristus dengan berbicara (speaking) dan juga mereka yang melakukan pelayanan dengan melayani (serving). Baik mereka yang melayani di mimbar (pulpit) dan juga di balik layar (behind the scenes) sama-sama memberikan kontribusi kepada gereja. Hal yang sama

${ }^{21}$ Sean Feucht dan Andy Byrd, Integrity: Character Of The Kingdom (New Kensington: Whitaker House., 2016), 18.

22 Baca. Suriawan Suriawan, "Kebergantungan Pengkotbah Terhadap Peran Roh Kudus Dalam Persiapan Dan Penyampaian Firman Tuhan," Abdiel 2, no. 1 (2018): 105-22, https://doi.org/10.37368/ja.v2i1.64 Bagian ini peneliti banyak terinspirasi dari artikel Suriawan. 
disampaikan oleh Suriawan yang menyebutkan bahwa "pengkhotbah adalah saluran tempat mengalirnya kebenaran Firman Allah. Oleh sebab itu, sifat dan kerohaniannya harus mantap." Shipman juga menyebutkan "para pengkhotbah melihat panggilan untuk berkhotbah sebagai berkat bagi mereka dari pada melihatnya sebagai orang yang berkedudukan atau selaku "pelayan jagoan" yang terhormat."23

Jika ada pengerja atau pelayan yang memiliki tanggung jawab untuk berkhotbah dalam pelayanannya (apakah kepada jemaat secara keseluruhan atau kepada kelas atau kelompok kecil), maka perlu memperhatikan hal-hal berikut: pertama jangan memberikan arahan atau koreksi. Kedua, hindari topik-topik yang kontroversi. Ketiga, jangan terlihat lebih hebat. Keempat, terima pujian dengan rendah hati. Dan kelima, jangan menata ulang perabotan. Maksudnya sebagai seorang pelayan, mungkin mereka tidak setuju dalam semua hal dengan gembalanya. Tetapi, jika pengerja di gereja tersebut di gereja sebagai bawahan maka pengerja ini harus setuju dengan gembalanya menurut sifat dasar Alkitab.

\section{Exercise discretion (berakal budi).}

Seluruh pengerja atau pelayan di gereja haruslah berakal budi. Kejadian 41:33 berkata "Oleh sebab itu, baiklah tuanku Firaun mencari seorang yang berakal budi dan bijaksana, dan mengangkatnya menjadi kuasa atas tanah Mesir.” Sebagai tambahan pemaparan dari karakter yang seharusnya dimiliki oleh semua pengerja atau pelayan di gereja seperti yang telah disebutkan di atas, maka pentingnya juga bagi semua pengerja atau pelayan di gereja untuk berfokus pada integritas (integrity), karakter (character) dan kredibilitas (credibility) yang penting bagi

23 Suriawan, 109. 
kemuliaan Tuhan dan memberikan pengaruh yang positif kepada jemaat atau orang-orang yang dilayani karena menurut Tony Cooke ${ }^{24}$, ada pengerja atau pelayan yang memiliki pemikiran bahwa adalah hal yang biasa jika mereka menjadi setia ketika Tuhan memberikan mereka tugas yang besar dan penting. Ada juga yang hanya melayani dengan setengah hati atau dengan usaha yang minim terhadap tugas pelayanan yang diberikan tersebut karena menurut mereka tugas pelayanan ${ }^{25}$ yang diberikan ini tidak besar atau menarik. Tetapi ini malah bertolak belakang sebab Yesus berkata penting untuk berlaku setia bahkan dalam hal kecil. Tidak dapat dipungkiri bahwa manusia sekarang hidup di zaman yang penuh dengan skeptisisme (skepticism) dan ketidakpercayaan (mistrust). Investasi bodong, pencurian identitas, korupsi, politikus bermuka dua dan skandal di gereja yang sudah menjadi bagian dari budaya modern yang tidak lagi mengejutkan masyarakat dewasa ini.

Oleh sebab itu dapat disimpulkan bahwa semua pengerja atau pelayan yang melayani di gereja hendaknya dapat mengadopsi dan mengembangkan sifat atau karakter positif dalam kehidupan pelayanan mereka. Karakter yang tercermin dalam pelayanan yang dilakukan oleh semua pengerja dengan penuh integritas dan kredibilitas tentunya akan memberikan pengaruh yang positif kepada jemaat di gereja di mana mereka melayani dan yang terpenting adalah semua yang mereka lakukan dan kerjakan adalah untuk kemuliaan Tuhan.

\section{Panggilan Melayani}

${ }^{24}$ Cooke, Qualified: Serving God With Integrity And Finishing your Course With Honor, 54-55.

25 Hasahatan Hutahaean, "Dan Siapapun Yang Memaksa Engkau Berjalan Sejauh Satu Mil, Berjalanlah Bersama Dia Sejauh Dua Mil Matius 5:41," dalam Tuhan Memberi Yang Terbaik: Kumpulan Refleksi Iman dan Pelayanan, ed. oleh Stenly R. Paparang (Luwuk: Pustaka Star's Lub, 2019), 19. 
Vujicic memberikan istilahnya dalam pertumbuhan secara alami dalam panggilan melayani yakni sebagai tangan dan kaki dari Yesus (as the arms and legs of Jesus), ${ }^{26}$ dimulai saat dia berumur tujuh belas tahun dan duduk di kursi roda. Nick Vujicic dilahirkan tanpa tangan dan kaki tetapi Tuhan memanggilnya dan memakainya menjadi berkat bagi orang banyak melalui pelayanannya.

Robert M. Solomon menjelaskan mengenai panggilan Tuhan dalam pelayanan dengan mencontohkan tokoh Yunus. Maukah setiap orang Kristen meresponi panggilan Tuhan? Solomon menyebutkan bahwa karakter utama dari Kitab Yunus adalah Tuhan, yang mana jika tidak ada Tuhan maka cerita mengenai Yunus tidak akan terjadi. ${ }^{27}$ Dalam Kitab tersebut menunjukkan bahwa Tuhan adalah seorang Pekabar Injil (a missionary God) di mana Dia mengambil inisiatif untuk menyelamatkan orang-orang berdosa dari kebinasaan. Dia juga yang telah mengutus Yunus ke Niniwe dengan pesan yang bisa membuat penduduk Niniwe bertobat dan Dia juga yang telah menyelamatkan setiap orang; orang-orang yang berada di perahu, seluruh rakyat Niniwe dan juga Yunus sendiri.

Makna panggilan melayani menurut Feucht dan Byrdyakni saat semua orang percaya sudah memulai perjalanan mereka dengan Yesus (dalam panggilan pelayanan) dan terpanggil untuk pelayanan kepemimpinan dalam kapasitas tertentu ("called to ministry leadership in some capacity") maka ada dua hal yang memasuki pikiran mereka. ${ }^{28}$ Yang pertama adalah bahwa mereka ingin agar mereka yang melayani-Nya bisa berguna bagi Tuhan dalam cara apapun yang dipilih-Nya untuk kemuliaan-Nya. Intinya, mereka ingin bisa sukses untuk Yesus.

${ }^{26}$ Nick Vujicic, Be The Hands And Feet: Living Out God's Love for All His Children (New York: WaterBrook, 2018), 19.

27 Robert M Solomon, God in Pursuit: Lessons from the Book of Jonah (Jakarta-Indonesia: Discovery House, 2017), 127.

28 Feucht dan Byrd, Integrity: Character Of The Kingdom, 75. 
Kedua, mereka ingin mengakhiri apa yang sudah mereka mulai dan melakukannya dengan terhormat, atau dengan kata lain, mereka ingin melayani dengan semaksimal mungkin dan mengakhirinya dengan baik.

Berdasarkan beberapa pemahaman mengenai panggilan melayani di atas, dapat disimpulkan bahwa setiap orang Kristen dipanggil untuk terlibat dalam pelayanan penuh waktu, baik di gereja maupun di marketplace dan sebagainya. Semua orang Kristen adalah pelayan Tuhan dan Tuhan tidak memandang dan memilih orang-orang dengan kapasitas atau fisik yang sempurna unuk melayaniNya. Semua orang Kristen adalah sama di hadapan Tuhan dan setiap pelayan yang sudah terpanggil untuk melayani-Nya tetap berada dalam perlindungan-Nya dan haruslah melayani dengan maksimal dan menyelesaikan tugas pelayanan mereka sampai akhir.

Untuk lebih mengerti lagi akan pengertian atau definisi panggilan melayani, maka diberikan contoh kisah panggilan melayani dari kedua tokoh pelayanan yakni William Carey dan Kenneth E. Hagin. Kedua tokoh ini benarbenar menunjukkan bukti panggilan melayani dalam diri mereka dan berhasil menyelesaikannya sampai akhir.

Tokoh pertama yakni William Carey (17 Agustus 1791-9 Juni 1834) berangkat ke Kalkutta, India murni panggilan dalam dirinya untuk melayani Tuhan. William Carey dan keluarga harus berpindah ke kota yang lebih kecil dikarenakan tidak mempunyai uang yang cukup untuk bisa tinggal di Kalkuta dan juga menghindar dari tentara Kerajaan Inggris dikarenakan mereka memasuki India sebagai imigran gelap. 
Dan dikarenakan kesetiaannya pada panggilan untuk benar-benar melayani Tuhan, Carey tetap tekun mempelajari bahasa-bahasa penduduk setempat. Bahkan di saat yang paling kelam sekalipun (dengan meninggalnya anak bungsu dan istrinya), dia tetap setia dengan panggilannya sebagai seorang misionaris.

Tokoh berikutnya adalah Kenneth E. Hagin (20 Agustus 1917-19 September 2003), dikenal sebagai seorang pengkhotbah (preacher), penginjil, gembala dan guru Alkitab. Hagin dilahirkan dengan kondisi cacat jantung dan penyakit pembuluh darah dan diyakinkan oleh dokter bahwa dia tidak akan hidup melewati usia remajanya. Di awal pelayanannya, tidak mudah bagi Hagin untuk melakukan perjalanan ke kota-kota lainnya di Amerika dan berkhotbah. Hagin banyak memberikan kesaksian hidupnya dan bahkan kesaksian dari temannya juga dalam hal pelayanan ke negara lain. Hagin telah membuktikan jika para pengerja atau pelayan bersungguh-sungguh melayani Tuhan sesuai dengan tuntunan-Nya, maka Tuhan tentu akan membantu hamba-hamba-Nya dengan membukakan jalan dan juga memberikan materi (finansial).

Kedua tokoh di atas (William Carey dan Kenneth E. Hagin) mempunyai "kesamaan" (similarities), di mana kedua tokoh ini sama-sama menekankan pentingnya sebuah "kesetiaan" dalam meresponi panggilan Tuhan dalam melayani yang didasarkan pada "iman."

Dari informasi singkat mengenai panggilan melayani kedua tokoh pelayanan di atas, dapat disimpulkan bahwa seharusnya semua pelayan atau pengerja di ladang Tuhan bisa belajar dan berpedoman pada apa yang sudah ditunjukkan oleh kedua tokoh di atas dalam hal panggilan melayani dan kesetiaan melayani Tuhan di dalam kehidupan mereka dan ini mungkin juga bisa menjadi 
dasar pemikiran dalam mendalami dan mengupas pemahaman pelayanan, panggilan pelayanan dan kesetiaan dalam melayani nantinya.

\section{Makna Panggilan Melayani}

Dalam bahasa Inggris Roma 8:28, terdapat kata "for good" (untuk kebaikan), "love" (mengasihi) dan "called" (terpanggil). Menurut Tim Peneliti, hal ini menunjukkan bahwa setiap orang percaya harus menunjukkan kasihnya kepada Tuhan dan terpanggil untuk tugas pelayanan dan Tuhan akan mendatangkan kebaikan bagi mereka yang melayani-Nya. Demikian juga David Pan Purnomo menjelaskan makna Roma 8:28 dengan menyebutkan mengapa setiap orang Kristen dipanggil untuk melayani dan bagaimana orang Kristen mengetahui panggilan Tuhan. ${ }^{29}$ Jawabannya adalah Roma 8:28 "Allah turut bekerja dalam segala sesuatu untuk mendatangkan kebaikan bagi mereka yang mengasihi Dia, yaitu bagi mereka yang terpanggil sesuai dengan rencana Allah.”

Tidak bisa dipungkiri bahwa di zaman modern dan kompetitif ini, terutama di marketplace, pastilah orang-orang dengan kemampuan yang lebih baik (berpendidikan, cerdas dan sebagainya) yang akan direkrut oleh perusahaanperusahaan. Tetapi apakah hal yang sama berlaku juga bagi pengerja yang ingin melayani di gereja?

Dalam masyarakat modern yang berkompetisi tinggi, perusahaanperusahaan dan organisasi-organisasi dunia hanya mau memakai orangorang yang "pandai, cakap, kuat dan mulia." Tetapi Tuhan memanggil segala macam orang yang "mengasihi Dia" (Roma 8:28) dan "yang kudus" (Efesus 4:12), untuk diperlengkapi bagi pekerjaan pelayanan. Istilah "diperlengkapi" ("katartismos", Efesus 4:12), boleh diterjemahkan "dipersenjatai" atau "disempurnakan". Syukur kepada Tuhan bahwa karena kerelaan melayani Tuhan, maka kita yang lemah dan bodoh "diperlengkapi" menjadi orang-orang yang pandai dan kuat. Seorang $57-59$.

29 David Pan Purnomo, Menjawab Pertanyaan-Pertanyaan Kontemporer (Malang: SAAT, 1994), 
tokoh iman yang bernama A.W. Tozer mengatakan: "Tuhan hanya dapat memakai orang yang selalu bersukacita dan tidak menolak didikan atau ajaran Tuhan., 30

Fakta di lapangan menunjukkan bahwa ada banyak orang yang melayani Tuhan secara "temporary" (sementara). Artinya, kalau mereka dalam keadaan "senang hati, lancar, banyak berkat dan dipuji” maka mereka bersedia melayani Tuhan. Akan tetapi sebaliknya, jika keadaan memburuk, maka mereka tidak lagi berminat untuk melayani. Ini mencerminkan sifat manusia yang egois. Harus diingat bahwa "Allah tidak menyesali kasih karunia dan panggilan-Nya" (Rom.11:29). Panggilan Tuhan bersifat "permanen" atau tetap dan bukan "sementara".

Kalau memperhatikan penjelasan untuk nas Roma 8:20 di dalam Life Application Study Bible yang menyebutkan:

God works in everything-not just isolated incidents-for our good. This does not mean that all that happens to us will be pleasant, and we do not have to call pain good. Even though evil pervades our fallen world, God is able to turn every circumstance around for our long-range benefit. Note that God does not work only to make us happy but to fulfill His purpose. Note also that this promise is not for everybody. It can be claimed only by those who love God and are called by Him-that is, those the Holy Spirit convinces and enables to receive Christ. Such people have a new perspective, a new mind-set. They trust in God, not in life's treasures; they find their security in heavenly priorities, not earthy ones. Their faith in God does not waver in pain and persecution because they know God is with them. ${ }^{31}$

Penjelasan di atas bisa diartikan bahwa Tuhan bekerja dalam segala sesuatu, bukan hanya pada kejadian-kejadian tertentu saja dan untuk kebaikan orang percaya. Tetapi ini bukan berarti semua yang terjadi pada orang percaya akan menyenangkan. Walaupun kejahatan melingkupi dunia setelah kejatuhan, Tuhan sanggup merubah setiap keadaan menjadi baik untuk jangka panjang. Perlu

30 Purnomo, 58.

31 Life Application Study Bible, Red Letter (Grand Rapids: Zondervan, 2017), 1960. 
dicatat bahwa Tuhan bukan hanya bekerja untuk membuat mereka bahagia melainkan untuk memenuhi tujuan-Nya. Perlu juga dicatat bahwa janji Tuhan ini bukan diperuntukkan bagi semua orang. Ini hanya berlaku bagi mereka yang mengasihi Tuhan dan terpanggil oleh Dia yakni mereka yang diyakinkan oleh Roh Kudus dan yang mau menerima Kristus. Orang-orang tersebut memiliki perspektif atau pandangan yang baru, pola pikir yang baru. Hasahatan juga menyatakan bahwa pekerja Tuhan sanggup meniadakan diri demi Tuhan yang dilayani. ${ }^{32}$ Mereka percaya kepada Tuhan, bukan kekayaan duniawi yang mereka cari melainkan mencari keselamatan yang menjadi prioritas utama. Iman mereka kepada Tuhan tidak goyah oleh penganiayaan dan penderitaan karena mereka tahu bahwa Tuhan menyertai mereka.

\section{KESIMPULAN}

Pemahaman pelayanan dari pengerja-pengerja di GBI My Family tahun 2019 masih terdapat persentase responden yang berada pada kategori interval kelas bawah yang kurang mendukung hipotesa. Berdasarkan uji kecenderungan maka di tabel 4 di atas perlu upaya meningkatkan pemahaman pelayanan pada diri para pengerja. Serta disarankan agar sebaiknya sistem pembinaan pengerja yang sudah diterapkan di gereja yakni melalui pelatihan (training) dari departemen pengajaran dan pelatihan GBI My Family perlu dilakukan dengan sesering mungkin. Pengerja di GBI My Family sebaiknya mengerti dengan benar makna panggilan melayani. Sebab para pengerja adalah pribadi yang mengasihi Tuhan

32 Hasahatan Hutahaean, "Memahami 'Menjadi Saksi' Tafsir Struktur Yesaya 44:1-8," dalam Menabur Kasih Menuai Jiwa, ed. oleh Stenly R Paparang (Jakarta: Departemen Literatur dan Media Arastamar (Delima), 2016), 181. 
dan terpanggil sesuai dengan rencana Tuhan. Hal ini perlu disampaikan kepada para pengerja melalui departemen pengajaran dan pelatihan GBI My Family yang mungkin bisa dilakukan dengan sesi khusus dalam menyampaikan topik tersebut. Dikarenakan masih terdapat persentase responden (pengerja GBI My Family) yang berada pada kategori interval kelas bawah yang tidak mendukung hipotesa, oleh sebab itu disarankan agar para pengerja GBI My Family harus memiliki sikap berpegang teguh dan dapat dipercaya dalam kehidupan pelayanan mereka dengan berpegang pada pedoman-pedoman yang berhubungan dengan kesetiaan, seperti belajar setia kepada sesama, gembala dan pemimpin (leader) yang berada di atas mereka serta menyadari bahwa Tuhan memberkati setiap pengerja yang setia. Seluruh pengerja di GBI My Family pada khususnya dan para pengerja termasuk juga para mahasiswa-mahasiswi Sekolah Tinggi Teologi Sumatera Utara (STTSU) yang nantinya terlibat dalam bidang pelayanan di ladang Tuhan atau misi. Dan perlu menjadikan penelitian ini sebagai salah satu bahan pedoman atau tambahan yang dapat dipergunakan untuk menjadi landasan dalam kehidupan pelayanan mereka. Terima kasih kepada gembala GBI My Family Pdt Lukgimin Aziz yang telah mendukung penelitian ini serta menjadi suvervisor bersama Gundari Ginting selama penelitian berlangsung.

\section{DAFTAR PUSTAKA}

Blackaby, Henry, dan Tom Blackaby. The Man God Uses. Singapore: B\&H Books, 2001.

Braga, Anthony A., David M. Hureau, dan Andrew V. Papachristos. “An Ex Post Facto Evaluation Framework for Place-Based Police Interventions." Evaluation Review 35, no. 6 (2012): 592-626. https://doi.org/10.1177/0193841X11433827. 
Cho, Yonggi, dan Wayde Goodall. Faith: Believing In The God Who Works On Your Behalf. Wisconsin: BroadStreet Publishing Group, LLC, 2017.

Cooke, Tony. Qualified: Serving God With Integrity And Finishing your Course With Honor. Tulsa: Harrison House, Inc, 2012.

Darmawan, I Putu Ayub. "Jadikanlah Murid: Tugas Pemuridan Gereja Menurut Matius 28:18-20." Evangelikal: Jurnal Teologi Injili dan Pembinaan Warga Jemaat 3, no. 2 (2019): 144-53. https://doi.org/10.46445/ejti.v3i2.138.

Feucht, Sean, dan Andy Byrd. Integrity: Character Of The Kingdom. New Kensington: Whitaker House., 2016.

Gulo, Manase. "Prinsip Integritas Berdasarkan Injil Matius 5:17-48 Dan Implementasinya Bagi Pelayan Tuhan Masakini." Manna Rafflesia 4, no. 1 (2017): 16-36. https://doi.org/10.38091/man_raf.v4i1.79.

Handayani, Dessy. "Isu-isu Kontemporer dalam Jabatan Gerejawi." Kurios 3 No.1 (2015): 66-75. https://doi.org/10.30995/kur.v3i1.28.

Horsfall, Tony. Servant Ministry: A Portrait Of Christ And A Pattern For His Followers. Abingdon: Bible Reading Fellowship, 2013.

Hutahaean, Hasahatan. "Dan Siapapun Yang Memaksa Engkau Berjalan Sejauh Satu Mil, Berjalanlah Bersama Dia Sejauh Dua Mil Matius 5:41." Dalam Tuhan Memberi Yang Terbaik: Kumpulan Refleksi Iman dan Pelayanan, disunting oleh Stenly R. Paparang, 18-23. Luwuk: Pustaka Star's Lub, 2019.

"Memahami 'Menjadi Saksi' Tafsir Struktur Yesaya 44:1-8." Dalam Menabur Kasih Menuai Jiwa, disunting oleh Stenly R Paparang, 171-82. Jakarta: Departemen Literatur dan Media Arastamar (Delima), 2016.

Jost, Kenneth. "Ex Post Facto." Dalam The Supreme Court A to Z, 5 ed., 197-197. CQ Press, 2014. https://doi.org/10.4135/9781452234373.n131.

Laia, Kejar Hidup. "Sikap Hamba Tuhan terhadap Jemaat yang Mundur dari Pelayanan.” Illuminate 3, no. 1 (2020): 40-60. https://doi.org/621-7732.

Life Application Study Bible. Red Letter. Grand Rapids: Zondervan, 2017.

Oladipo, Emmanuel. Flawed Saints. Disunting oleh Hans Wuysang. Jakarta: Pancar Pijar Alkitab, 2014.

P.D, Sugiono. Metode penelitian pendidikan pendekatan kuantitatif.pdf. Metode Penelitian Pendidikan Pendekatan Kuantitatif, Kualitatif Dan R\&D, 2014. 
Prihanto, Agus. "Peran Proses Mentoring Pemimpin Kaum Muda Bagi Perkembangan Pelayanan Pemuda Di Gereja." Jaffray 16, no. 2 (2018): 175-96. http://dx.doi.org/10.25278/jj71.v16i2.258.

Purnomo, David Pan. Menjawab Pertanyaan-Pertanyaan Kontemporer. Malang: SAAT, 1994.

Solomon, Robert M. God in Pursuit: Lessons from the Book of Jonah. JakartaIndonesia: Discovery House, 2017.

Stevanus, Kalis. "Mengimplementasikan Pelayanan Yesus Dalam Konteks Misi Masa Kini Menurut Injil Sinoptik." FIDEI: Jurnal Teologi Sistematika dan Praktika 1, no. 2 (2018): :284-298. https://doi.org/10.34081/fidei.v1i2.21.

Sugiyono. "Metode Penelitian Kuantitatif,Kualitatif dan R\&D.” Ke-26, 2018.

Suharsimi, Arikunto. "Prosedur Penelitian: Suatu Pendekatan Praktik (Edisi Revisi)." Rineka Cipta, 2010. https://doi.org/10.1017/CBO9781107415324.004.

Supriadi, Made Nopen, dan Iman Kristina Halawa. "Makna Penderitaan Kristus Dalam 1 Petrus 2:18-21." Manna Rafflesia 5, no. 1 (2018): 69-91. https://doi.org/10.38091/man_raf.v5i1.99.

Suriawan, Suriawan. "Kebergantungan Pengkotbah Terhadap Peran Roh Kudus Dalam Persiapan Dan Penyampaian Firman Tuhan." Abdiel 2, no. 1 (2018): 105-22. https://doi.org/10.37368/ja.v2i1.64.

Towns, Elmer L, dan Dave Earley. Praying for Your Job-Prosperity, Fulfillment, Happiness. Shippensburg: Destiny Image Publishers, Inc, 2011.

Vujicic, Nick. Be The Hands And Feet: Living Out God's Love for All His Children. New York: WaterBrook, 2018.

Wahidmurni. "Penerapan Metode Penelitian Kuantitatif." Repository UIN Malang 1, no. 1 (2017): 287-295. 